\title{
Mídia comunitária e novas construções periféricas sociais no Brasil
}

\section{Rosana Martins}

Cientista Social pela Universidade de São Paulo (USP). Mestre e doutora em Ciências da Comunicação pela Escola de Comunicações e Artes da USP. Pósdoutoranda e pesquisadora do Centro de Investigação Media e Jornalismo (CIMJ), Universidade Nova de Lisboa, membro do The Transnational Lives, Gender and Mobility network (TLM \& G) - Institute of Social Sciences University of Lisbon / European Science Foundation.

E-mail: rosanasantosposse@yahoo.com.br
Resumo: $O$ presente ensaio visa analisar a articulação teórica em torno dos conceitos de representação, esfera da visibilidade e reconhecimento social, a fim de retratar o nomeado "cinema de periferia", suas instâncias de produção e difusão. Procuro identificar a importância dada à conquista de espaços em termos de visibilidade e a postura dos coletivos periféricos, emergindo numa conjuntura social cada vez mais atravessada por uma multifacetada gama de ambivalências circunscritas na metrópole como centro de difusão e consumo de imaginários culturais, no contexto de uma sociedade marcada por rupturas no sentido da racionalidade humana embrutecida pelo capital.

Palavras-chave: mídia comunitária; audiovisual; periferia; hip-hop; identidade; protagonismo social.

\section{Title: Community media and new social periphery buildings in Brazil}

Abstract: This paper analyzes the theoretical articulation around the representation of concepts, visibility sphere and social recognition, in order to portray the named 'periphery film', your instances of production and dissemination. I seek to identify the importance given to the conquest of space in terms of visibility and the position of the peripheral collective, emerging into a social situation increasingly crossed by a multifaceted range of ambivalence circumscribed in the metropolis as a center for dissemination and consumption of cultural imagery in the context of a society marked by breaks in the sense of human rationality brutalized by capital.

Keywords: community media; audiovisual; periphery; hip-hop; identity; social protagonism 


\section{Representatividades periféricas}

Por periferia entendo o espaço que está no entorno, na vizinhança, de outro espaço tido como central, de onde surgem as reflexões quanto ao espaço de exclusão sócio-territorial. Esta se encontra quase sempre associada à ideia de conflito, a partir do momento que passa a incorporar valores de um espaço urbano sobre outro. Teresa Caldeira, em seu livro City of Walls (2000), aponta a segregação tanto como um fenômeno social quanto espacial, e as regras que organizam o espaço urbano passam pela questão da diferencial social e de separação.

O gueto, ou periferia, constituem uma espacializada racialização, onde o estigma racial e a significação moral da diferença são reforçados pela estruturação da desigualdade racial

1 "Como uma característica estrutural da vida urbana moderna, o gueto é uma estratégia administrativa de racialização imposta pelo Estado, um mecanismo de controle social, através aviltamento moral que serve um papel estrutural importante para reforçar a estratificação social através da significação da diferença moral dentro do corpo"
As a structural feature of modern urban life, the ghetto is an administrative strategy of state-imposed racialization, a mechanism of social control through moral debasement that serves a critical structural role by reinforcing social stratification through the signification of moral difference within the body ${ }^{1}$. (HUTCHISON; HAYNES, 2012, p. XV)

Kowarick $(1983,2000)$ reforça que falar em periferia implica falar no plural, pois além de indicar a distância geográfica e o que é precário, carente, desprivilegiado em termos de serviços públicos e infraestrutura básica (ruas irregulares e esburacadas, ausência de serviços como iluminação pública e asfalto, graves problemas de saneamento, transporte, serviços médicos e escolares), esquece-se de registrar, sobretudo, que a periferia também é um espaço de sociabilidade, de arte e de intervenção político-cultural.

Nesse sentido, quando falo em centro e periferia estou falando não apenas de espaços apenas mensuráveis em dimensão, condições socioeconômicas e infraestrutura, mas também na construção das representações sociais - como por exemplo a visibilidade produzida pelas grandes mídias sobre a periferia: espaço do caos e da violência, sendo espaços permeados pela criminalidade, o lugar da ausência de garantias legais e regida por leis próprias. Portanto, criamse estereótipos que se reproduzem tendo como matriz a redução das periferias (e favelas) à pobreza, ao crime e à violência, como se estes fossem as marcas identificadoras daquilo que está à margem da civilização, da cidadania e da legalidade institucional.

Para Bonduki e Rolnik (1982), a periferia é definida a partir da aquisição da moradia popular vinculada à reprodução da força de trabalho da população de baixa renda. Os autores destacam a indiscriminada utilização do termo, em uma perspectiva geográfica, a partir da distância do centro e, em uma perspectiva sociológica, na configuração de espaços de reprodução da força de trabalho que são relacionamos à pobreza, desprestígio, e, por extensão, invisibilidade. Nesse sentido, procuram formular uma definição mais precisa, conceituando a periferia como "parcelas do território da cidade que têm baixa renda diferencial" (BONDUKI; ROLNIK, 1982, p. 147). A renda diferencial corresponde às diferenças de localização, condições físicas, e aos investimentos aplicados sobre o terreno.

Nesse caso, Raquel Ronike Nabil Bonduki (NAKANO, 2002), ao definirem a periferia baseada na baixa renda diferencial que a terra recém urbanizada possui devido ao baixo nível de investimentos em serviços e equipamentos urbanos, realizam o paralelo com a macrossegregação produzida pelo diferencial na capacidade social de acesso à terra urbana mantida como uma mercadoria peculiar na urbanização capitalista, cujos benefícios são acessados notadamente por aqueles com maior poder aquisitivo. Pode-se dizer que o conceito de macrossegregação 
é intercambiável com a exclusão social que também opera interdições de acessos aos serviços e benfeitorias urbanas produzidas coletivamente. Cabe ressaltar que a localização das pessoas no território é, na maioria das vezes, produto de uma combinação entre forças de mercado, planos que respondem aos interesses do capital empreendedor e decisões de governo.

Pode-se dizer, então, que numa sociedade cujos princípios são traçados pela estética do mercado, a exclusão social é por si só uma violência provocada pela estrutura social, que reflete no cotidiano por intermédio da privação das classes subalternas no acesso aos bens materiais, simbólicos e sociopolíticos. Ainda que sublinhar a cultura da pobreza como fator atrelado à natureza, neste caso, desvie a atenção das próprias relações de poder e alimente as políticas públicas que perpetuam a desigualdade e a incivilidade social ancoradas no imaginário que fixa a pobreza como marca da inferioridade, a mercê da filantropia pública, de um sistema social em crise (PAOLI; TELLES, 2000).

É a partir dos anos noventa que teremos o desencadeamento de diversas realizações televisivas e cinematográficas que procuraram reelaborar o espaço periferia como foco privilegiado de atenção (HAMBURGER, 2007). Se por um lado a periferia é novamente retratada como o espaço à parte da cidade, com ausência do Estado e regida por seus códigos próprios, e seus moradores são tidos como meros objetos de ações, leituras e visões, negando-lhes a sua condição de

${ }^{2}$ Criada em 1995, a Associação Cultural Kinoforum, entidade sem fins lucrativos, realiza atividades e projetos e apoia o desenvolvimento da linguagem e da produção cinematográfica com destaque para a promoção do audiovisual brasileiro, a partir de intercâmbio com associações e eventos nacionais e internacionais. A entidade é responsável também por diversas atividades como o Curta Kinoforum - Festival Internacional de CurtasMetragens de São Paulo, Festival de Vídeo Tela Digital, as Oficinas Kinoforum de Realização Audiovisual, o Guia Kinoforum de Festivais de Cinema e Vídeo, site kinooikos.com, kinolounge e Crítica Curta. Cf. ASSOCIAÇÃO CULTURAL KINOFORUM,s.d, s.p.

${ }^{3}$ A Ação Educativa, é uma associação civil sem fins lucrativos fundada em 1994 com objetivo de promover direitos educativos, culturais e da juventude, visando a justiça social, a democracia participativa e o desenvolvimento sustentável. A associação vem realizando atividades de formação e apoio a grupos de educadores, jovens e agentes culturais, além de integrar campanhas e outras ações coletivas que visam a realização desses direitos, no nível local, nacional e internacional. Para tanto, a entidade procura desenvolver pesquisas enfocando as políticas públicas na perspectiva dos direitos humanos e da igualdade étnico-racial e de gênero. A sede funciona em São Paulo, capital, e vem contanto com diversas agências de financiamento a nível nacional e internacional.Cf. AÇÃO EDUCATIVA, s.d, s.p. protagonistas e atores de suas próprias vidas, por outro avista-se uma nova vertente que traz a público outras experiências e, acabam por optar por uma abordagem marcadamente diferenciada sobre a periferia, ao investir num discurso positivo, associado às ideias de diversidade cultural, espírito comunitário, criatividade, solidariedade etc., em oposição à violência, desigualdade, criminalidade, exclusão etc. (embora estes aspectos possam estar presentes).

A comunicação, como bem afirma Martin-Barbero (1997), é uma questão de culturas, de sujeitos e não só de aparatos e estruturas; é uma questão de produção, e não só de reprodução. É nesse horizonte que salienta-se que entender a cultura como o espaço das práticas sociais é entender essas práticas como o espaço em que as relações sociais adquirem concretude.

Certamente, se nos últimos anos, à associação imediata entre periferia e pobreza (VALLADARES, 2005) adicionou-se a violência urbana e a criminalidade, seja por parte da grande mídia ou no discurso das classes médias e altas, de uma outra maneira jovens moradores das periferias criaram respostas para esse discurso, que através das artes começam a atuar nas periferias em iniciativas que visavam repensar o espaço público, a cidadania, as políticas públicas e o papel político das organizações governamentais. Com o boom do movimento hip-hop, nos anos noventa, a periferia começou a ser vista por muitos jovens com sentimento de orgulho, o que provocou inclusive o interesse de jovens de classe média e alta pela "estética periférica". Com a música dos Racionais MC's, por exemplo, a região da zona sul de São Paulo passou a ser comentada pelos jovens, despertando curiosidade em quem não a conhecia e orgulho para quem lá vivia (MARTINS, 2005; NOVAES, 2006).

Neste mesmo período destaca-se o uso dos meios de captação de imagens por segmentos populares periféricos, que devido ao avanço tecnológico acabaram por tornar acessível a compra dos equipamentos, impulsionando a partir daí toda uma produção fílmica local.

Entretanto, vale notar também a forte presença incentivadora de oficinas voltadas a esse segmento oriundas de entidades não governamentais como Kinoforum ${ }^{2}$ e Ação Educativa ${ }^{3}$, em São Paulo. Seguindo nessa conjuntura, observase, em meados de 2000, o surgimento de grupos independentes periféricos, e, a partir de 2005, o aumento de produções dos mesmos segmentos já praticamente 
quase sem "incentivo" destas ONGs (LEITE, 2006). Atualmente muitos espaços considerados "de periferia" já dispõem de seus próprios canais de comunicação, como festivais próprios de cinema e realizações de curta metragem.

Foi no final do século XX que se observou uma verdadeira "revolução tecnológica" decorrente do avanço técnico nos campos das telecomunicações e da informática, colocando à disposição da sociedade possibilidades novas de comunicar e de produzir e difundir informação. O conjunto das chamadas "indústrias culturais" (rádio, cinema, televisão, impressos) vive uma mutação tecnológica sem precedentes com a digitalização que, embora longe de ter esgotado seus efeitos, já delineia uma nova paisagem comunicacional e informacional.

O uso das novas tecnologias de telecomunicação nas duas últimas décadas passaram por três estágios distintos, conforme Castells (1999) se refere: "a automação de tarefas, as experiências de usos e a reconfiguração das aplicações" (p. 50). Nos dois primeiros estágios, o progresso da inovação tecnológica baseou-se em aprender "usando". No terceiro estágio, os usuários aprenderam a tecnologia "fazendo", o que acabou resultando na reconfiguração das redes e na descoberta de novas aplicações.

Da "aldeia global" passamos à "sociedade da informação ou do conhecimento", e sobretudo, à "sociedade em rede", com suas utopias e aporias (inteligência coletiva, autonomia, democratização da cultura, realidade virtual...). O ciclo de realimentação entre a introdução de uma nova tecnologia, seus usos e seus desenvolvimentos em novos domínios torna-se muito mais rápido no novo paradigma tecnológico. Consequentemente, a difusão da tecnologia amplifica seu poder de forma infinita a medida que os usuários apropriam-se dela e a redefinem

Pode-se afirmar que através da ferramenta do audiovisual surge nas periferias uma práxis que acaba por envolver os agentes comunitários e sua população propriamente dita.

Os indivíduos constroem representações sobre a própria estrutura social e as clivagens sociais, e é no quadro das categorias oferecidas por essas representações que se auto-posicionam e desenvolvem redes de relações [...]. (VALA; MONTEIRO, 2004, p. 495)

As tentativas de explicação do mundo e dos objetos sociais constituem-se como representações sociais e se revelam nas falas e ações dos indivíduos. Logo, representar não significa reproduzir ou duplicar, significa muito mais que isso, reconstruir. Para Moscovici (1978), representar é participar ativamente da construção da sociedade e, sobretudo, de si.

Nesse sentido, o audiovisual produzido nos espaços periféricos cria toda uma nova atmosfera no reprossessamento dos fluxos comunicativos por meio dos quais uma sociedade se narra, reflete sobre si mesma e se reinventa, assim como se torna importante para que perspectivas e discursos sistematicamente invisibilizados se façam notáveis publicamente.

Em linguagem arendtiana, pensar em relação dialógica é remeter a outro princípio: a não autonomia do discurso, a incapacidade de liberdade e capacidade de julgamento, sintonizado no pensamento da autora com a ideia de totalitarismo, ou seja, a produção de sujeitos supérfluos, o eu sem interlocutor que não acolhe a pluralidade de experiências. Portanto,

[...] a ação e política, entre todas as capacidades e potencialidades da vida humana, são as únicas coisas que não poderíamos sequer conceber sem 
ao menos admitir a existência da liberdade, e é difícil tocar em problema político particular sem, implícita ou explicitamente, tocar em um problema de liberdade humana [...] a raison d'être da política é a liberdade, e seu domínio de experiência é a ação (ARENDT, 1979, p. 191-192).

No pensamento de Hannah Arendt, a política aparece reumanizando o mundo através da palavra, do discurso, da ação que surge com o senso partilhado, com a capacidade de distinguir o mundo com clareza. Hannah Arendt é aqui também uma referência muito particular, com a acentuação que põe no espaço público e que tem de ser defendido num espaço de liberdade e não dependente das pressões e interesses particulares.

A luta por autorrepresentação das periferias brasileiras vem acompanhada por uma busca de visibilidade pública, o que implica no uso de estratégias de "contraposição argumentativa" a fim de defender interesses coletivos. Nesse sentido, também pode ser compreendida como parte de uma luta por reconhecimento social (HONNETH, 1996).

A importância do agir conjunto, do qual nasce o poder, é entendido aqui como um recurso gerado pela capacidade dos membros de uma comunidade política de concordarem com um curso comum de ação, são os modos pelos quais os seres humanos se manifestam uns aos outros, não como meros objetos físicos, mas enquanto homens libertários. Logo, a apropriação dos meios e linguagens audiovisuais pelos periféricos reforça um discurso de autorrepresentação.

Nos escritos de Hall (1997), o conceito de representação aparece no campo da comunicação como forma expressiva que alimenta o ciclo recursivo por meio do qual sociedade e indivíduos constroem-se mútua e permanentemente. Desse modo, o audiovisual periférico contribui para a pluralização da esfera pública e, sobretudo, no surgimento de novas possibilidades expressivas para que diferentes perspectivas circulem pela sociedade.

O aporte dos Estudos Culturais para a compreensão da cultura é particularmente significativo para nossas observações, uma vez que considera o caráter ativo e processual do sistema social, contemplando também as forças oposicionais e alternativas que lutam para adquirir expressão e espaço. Para os estudos de comunicação, portanto, este conceito contribui para um afastamento da interpretação dos processos de comunicação exclusivamente como dominação e reprodução, uma vez que a hegemonia é sempre um processo e não existe apenas passivamente como forma de dominação.

É sob essa perspectiva que pensamos ser possível ressignificar o papel dos meios de comunicação na sociedade, entendendo-a como parte constitutiva deles, e eles como parte dela.

\section{Práticas culturais e identitárias}

No extremo sul da cidade de São Paulo, no Jardim Ângela, um lugar que já foi conhecido como Triângulo da Morte devido à alta taxa de homicídio, nasceu um movimento que tem por objetivo preencher o vácuo existente entre os meios de

\section{${ }^{4}$ Cf. BECOS E VIELAS, s.d.}

${ }^{5}$ Implementado pela prefeitura de São Paulo em 2004, esse programa concede apoio financeiro destinado à execução de iniciativas artísticoculturais encabeçadas por jovens de baixa renda, moradores de regiões da cidade em que os recursos e equipamentos culturais são escassos ou inexistentes. representação, a periferia e o poder institucional. O projeto "CineBecos" ${ }^{4}$ surgiu em 2005 a partir do grupo de jovens que mantinham o jornal Becos e Vielas no Jardim Ângela. Aos poucos foram somadas outras iniciativas além do trabalho de exibição, como a produção de um Cine Jornal, a realização de curtas metragens e a parceria com outros artistas e coletivos da cidade. As exibições começaram de forma alternativa, com equipamentos e espaço emprestados por escolas e amigos. No início de 2006, o coletivo conseguiu implantar um projeto apoiado pela Valorização de Iniciativas Culturais ${ }^{5}$ (VAl) o que possibilitou, para muitos coletivos e núcleos independentes de São Paulo, angariar recursos para seus próprios 
${ }^{6}$ Pontos de Cultura, principal ação do Programa Cultura Viva, voltado para o financiamento de entidades reconhecidas pelo ministério como aptas a desenvolver ações culturais. Os projetos aprovados por edital público recebem uma verba no valor de $\mathrm{R} \$$ 185 mil, em cinco parcelas semestrais, para investir no projeto apresentado. A novidade desse programa está no modo como são vistas as manifestações culturais populares. Se nos anos 1980 prevaleceram as políticas públicas com a intenção de ocupar os menos abastados (com o esporte, por exemplo) para que eles não se tornassem um problema social, hoje tais políticas não pensam o investimento em cultura apenas como uma questão de 'inclusão'. Inversamente, aposta-se na capacidade de gerência e autonomia das comunidades, grupos e instituições que se voltam para produções artístico-culturais.

\author{
${ }^{7}$ Cf. ASSOCIAÇÃO AUDIOVISUAL \\ CINESCADÃO, s.d.
}

projetos. Isso levou o coletivo a adquirir alguns equipamentos e a expandir as exibições, além de promover sessões itinerantes. Cabe ressaltar que programas como o VAl e os Pontos de Cultura ${ }^{6}$, por exemplo, deram outra perspectiva às políticas culturais em diversas partes do país ao estimular e fomentar projetos voltados às práticas cotidianas em suas variadas composições.

Há mais de um ano há exibições de filmes com temas diversificados no CineBecos seguidas de debates acerca dos mais diversos assuntos. Divulgar as manifestações artísticas e estabelecer parcerias com as produções audiovisuais da região passou a ser também um dos objetivos do coletivo, que procura sempre manter um espaço permanente para divulgação da produção audiovisual não comercial, dando prioridade à produção independente de realizadores e coletivos de todo o Brasil, propondo uma reflexão acerca das representações da periferia na mídia e das novas imagens construídas, exibidas e discutidas pelo CineBecos e por outros coletivos.

As projeções do CineBecos são realizadas nos "becos" da região, exibindo desde filmes clássicos até vídeos produzidos ali mesmo, na periferia. $O$ projeto é coordenado por Rogério Pixote, estudante de multimeios que vinha se sentindo desconfortável com as abordagens da periferia no cinema, já que as representações do real muitas vezes ganham a forma espetáculo, naturalizando desigualdades sociais e, sobretudo, negando qualquer possibilidade de reconhecimento dos sujeitos sociais que habitam as periferias. Portanto, nega-se, com isso, quaisquer possibilidades do reconhecimento de uma identidade própria construída a partir das múltiplas vivências no espaço popular.

A imagem da violência na periferia, cultivada de fora para dentro, tende a ficar em segundo plano no CineBecos. A crença no poder de modificação social por meio da arte dá ainda mais força a esses produtores culturais, que, comprometidos com suas origens, revelam que um maior "grito" somente está começando a urgir.

Outro exemplo que cito é o Núcleo Audiovisual Cinescadão ${ }^{7}$, criado em 2007 pelo Flávio Galvão, morador da zona norte de São Paulo. De acordo com Galvão (2013), foi a partir do momento que o grupo passou a funcionar como associação com registro no CNPJ (Cadastro Nacional da Pessoa Jurídica, onde todas as pessoas jurídicas e as equiparadas - pessoas físicas que exploram em nome individual atividades com intuito de lucro -, são obrigadas a se inscrever antes de iniciar as suas atividades) que se viu diante de dificuldades tanto de ordem burocráticas de se manter uma programação constante e também no quesito de burocracias de ordem jurídica e legal a ser cumprida.

O grupo que já contou com apoio monetário de um pequeno supermercado da região em 2009 ganhou um prêmio do fundo nacional do governo na categoria hip-hop e comunicação. Com o valor do prêmio somado a outros trabalhos do grupo e dinheiro pessoal dos integrantes, o coletivo conseguiu comprar uma casa no morro do Jardim Peri, onde funciona a sede do Cinescadão.

Cinescadão é uma manifestação artística e sócio-cultural, que teve suas primeiras realizações nas escadarias do morro do Jardim Peri, zona norte de São Paulo, onde a música, sobretudo o rap e o vídeo, encontram seu espaço, mas que, segundo Galvão, muitas vezes não funcionou com essa apresentação conjunta devido a energias divergentes. $O$ projeto também tentou abarcar o público infantil, mas de acordo com Galvão, não teve muita repercussão, já que as condições precárias do local inviabilizavam a atenção por longas horas desse tipo de público. Cabe ressaltar que os filmes eram exibidos a céu aberto e a plateia se acomodava nas escadarias de cimento do morro, lugar de passagem dos moradores da região.

Em conversa, realizada por e-mail no dia 8 de julho de 2014, Flávio Galvão relata que um dos motivos para o "esfriamento" (deixar de existir) das atividades ao ar 
${ }^{8}$ Empresa de telefonia brasileira subsidiária da Telecom Itália. livre do Cinescadão se deve ao fato de alguns integrantes do grupo, na época, tornarem-se evangélicos; outro fator foi o falecimento de morador que os acolhia no escadão; além disso tem-se a mudança de outros dois (inclusive do morador que disponibilizava a janela e parede de sua casa pra exibição). Entretanto, o fator primordial se deve a um tipo de "disputa interna" de prestígio e poder quando um integrante recém-chegado à associação apresentou um projeto que teria a TIM $^{8}$ como financiadora. O projeto foi recusado por uma parte do grupo, levando a sua divisão e, consequentemente, ao cessar de algumas atividades.

Recentemente, a Associação Audiovisual Cinescadão foi selecionada pelo Ministério da Cultura do Brasil para atuar como Ponto de Cultura, e um dos objetivos do grupo será a reforma e construção da sala de cinema na casa do Cinescadão, além de uma rádio comunitária em parceria com o grupo Cada Gênio do Beco (CA.GE.BE) - grupo de rap brasileiro fundado na cidade de São Paulo e formado por Cezar Sotaque, Shirley Casa Verde e DJ Paulinho.

O Cinescadão serve como frente de comunicação e difusão de vídeos na capital paulista, sendo vinculado à Fabicine, A Fantástica Fábrica de Cinema (composta em 2005 a partir do Fórum de Cinema Comunitário de São Paulo), grupo independente de pessoas que estabelece interlocução entre o cinema e a comunidade tendo o cinema como uma ferramenta política e instrumentalizadora para uma discussão local.

O sonho inicial do Cinescadão era criar uma estratégia de comunicação alternativa dentro da região norte, a necessidade de ter a produção do audiovisual que não chega pra população em geral por vários motivos. Vivemos numa estrutura de camisa de força que é a forma de exibição e estrutura comercial. São poucas salas de exibição de cinema em São Paulo, e essas salas não dão conta, sobretudo da grande produção audiovisual dentro do próprio país. (GALVÃO, 2013, s.p.)

É importante destacar que tais coletivos desempenham um papel muito importante na democratização da informação nas periferias e no exercício de repensar a prática da cidadania, tanto no sentido da ampliação do número de canais de informação e na inclusão de novos emissores, como no fato de se constituir em processo educativo, não só pelos conteúdos emitidos, mas pelo envolvimento direto das pessoas no "fazer comunicacional".

Melucci (1985) enfatiza suas análises voltadas ao questionamento das relações desenvolvidas no plano micro, na ação coletiva de indivíduos, tendo um enfoque mais psicossocial. A ação coletiva é vista como a união de vários tipos de conflitos baseados no comportamento dos atores num sistema social. Aqui os coletivos audiovisuais periféricos são sistemas de ações, redes complexas entre os diferentes níveis e significados da ação social. Logo, chama-se atenção para um conjunto de jovens realizadores de arte e cultura que vêm estabelecendo outras posições e referências de construção de significados da periferia pelos que vivem na periferia.

Há um discurso que demarca a existência de um tipo específico de produção ("audiovisual popular", "núcleos populares de formação audiovisual", "produções periféricas"), de periférica na plataforma do audiovisual. Logo, olhando para uma periferia plural e, sobretudo, diversa, Galvão (idealizador do Cinescadão) alerta sobre o perigo de se rotular a marca "da periferia" ou "made periferia".

É complicado você se intitular como cinema de periferia porque ele acontece na periferia, e o simples fato de ele acontecer na periferia será que é o suficiente pra gente dizer que é uma coisa tão presa a periferia, só da periferia. O homem da periferia, o ser humano, ele tá ligado à cidade como um todo, ao conhecimento da cidade, às trocas de relações, trocas materiais (GALVÃO, 2013, s.p.) 
Estamos diante de novas práticas estéticas reclamadas para o reconhecimento da realidade social, novas concepções de registro, novas constituições de plateias, novos mercados de distribuição das produções. Sob esta perspectiva, o espaço desenvolvido pelos coletivos periféricos apresenta-se como processo de propostas, de discussões e de negociações que acabam por se amplificar numa esfera maior da arena pública.

\section{Periferia voz ativa}

${ }^{9} \mathrm{Cf}$. CUFA, s.d

Central Única das Favelas - ou CUFA ${ }^{9}$, como costuma ser chamada -, situada em Madureira, zona norte da cidade do Rio de Janeiro, se transformou aos poucos num dos maiores polos culturais do país.

A CUFA é uma organização fundada em 1998 por moradores de diversas favelas do Rio de Janeiro, negros em sua maioria, e originários do movimento hip-hop. Dentre eles, destacam-se nomes da rapper Nega Gizza (uma das produtoras do Prêmio e do Festival Hutúz, que é o maior festival de hip-hop da América Latina, além de ser a presidente do núcleo MariaMaria, criado pela CUFA com projetos direcionados somente para mulheres e, presidente da Liga Internacional de Basquete de Rua (LIBRA), com competições e capeonatos em todo o território nacional), de MV Bill (rapper, escritor e documentarista, é outro membro fundador da CUFA) e de Celso Athayde (um dos mais importantes produtores de "cultura de rua" no Brasil), que juntos tornaram-se referência dentro do movimento hiphop por se colocarem como porta-vozes dos moradores das favelas cariocas na denúncia e combate às injustiças sociais. Juntos, produziram e dirigiram o documentário Falcão - Meninos do Tráfico (2006), escreveram o livro Falcão: mulheres e o tráfico (2007) e, em parceria com Luiz Eduardo Soares, escreveram "Cabeça de porco".

[...] a gente sempre percebeu que nossa história era contada através do olhar de outras pessoas, a história da favela, a história dos pretos, contada através de um outro olhar, o olhar de fora, e a gente percebeu que a gente tinha que mudar uma coisa no Brasil, que era que a gente não tinha registro da nossa vivência, da nossa história. Então a partir daí a gente começou a registrar tudo que a gente fazia, tudo que a gente, as nossas ações, nossas reuniões [...] a oportunidade de deixar para o futuro algo, para deixar desse momento da nossa história [...] a gente se importa em querer ser participativo, sempre pautando os políticos e a política brasileira, levando ideias e propostas, pensa o projeto e oferece o projeto, a partir do ponto de vista dos favelados, dizendo o que a gente quer, hoje mais preparado, hoje a gente quer ser ouvido, a gente bate na porta e pede (GIZZA, 2013, s.p.)

Essas vozes da periferia destituem os tradicionais mediadores da cultura, passando de "objetos" a sujeitos do discurso, contribuindo com uma renovação do político e com os discursos mais contundentes sobre racismo, violência policial ou pobreza.

A equipe CUFA é composta, em grande parte, por jovens formados nas oficinas de capacitação e profissionalização das bases da instituição e oriundos de camadas menos favorecidas da sociedade.

A CUFA possui, somente na cidade do Rio de Janeiro, cinco bases de atuação: CUFA Cidade de Deus, CUFA Viaduto de Madureira, CUFA Pedra do Sapo, CUFA Acari e CUFA Manguinhos. Além disso, a "chama CUFA" encontra-se acesa em mais de 27 estados do Brasil e vem desenvolvendo projetos em educação, meio ambiente, cultura e esportes. Desde 2009 a CUFA vem abrindo campos para outros projetos sociais em diveros país, tais como Argentina, Áustria, Bolívia, Chile, Alemanha, Haiti, Hungria, Itália Espanha e Estados Unidos da América. 
A CUFA Cidade de Deus (CUFA-CDD) foi a primeira base da CUFA no Brasil e é considerada a "matriz" da ONG; soma-se a isso, é claro, o fato de a Cidade de Deus ser o local de origem e moradia de um dos fundadores da entidade, o rapper MV Bill.

Para além destes aspectos, a base da Cidade de Deus foi escolhida como campo de observação porque abarcava oficinas de atividades culturais diversas. Dentre as ações inclusivas da CUFA (as oficinas são gratuitas para toda comunidade) e que dão legitimidade ao trabalho desenvolvido, destacamos, entre outros, o Núcleo de Audiovisual, inaugurado com a aula do diretor de cinema brasileiro Cacá Diegues e batizado em 2004 com a sigla CAV (Curso de Audiovisual). Aqui é oferecida ao CAV uma parceria de estágio com a produtora de Cacá Diegues, a Luz Mágica. Alguns alunos foram selecionados para usufruir daquela oportunidade.

O curso, que acontece aos sábados, é respaldado com aulas teóricas por um renomado grupo de cineastas brasileiros: Joel Zito, João M. Salles, Eduardo Coutinho, Silvio Tendler e outros mestres como Julio César Tavares, José Carlos Avellar, Ivana Bentes, Luiz Erlanger, Rafael Dragaud, Jorge Coutinho, Consuelo Lins, Felipe Muanis, Ângela Sander, como também a colaboração da ECO, Escola de Comunicação da Universidade Federal do Rio de Janeiro.

O curso que já ganhou a capa do segundo caderno do reconhecido jornal carioca $O$ Globo se caracteriza pela a metodologia de "alfabetização audiovisual" - produzemse filmes de curta-metragem, de caráter ficcional ou documental, em que podem exercitar a capacidade técnica e artística, além de participar do circuito exibidor dos festivais de cinema e estabelecer contatos para a entrada no mercado de trabalho audiovisual. Voltado para a transformação e ampliação das perspectivas profissionais e pessoais, o curso promove a inserção no mercado de trabalho, além de contribuir de forma determinante na elevação da autoestima dos jovens, visando incluir jovens de camadas menos favorecidas e formar alunos multiplicadores de conhecimento - agentes protagonistas no retrato da sua história.

E o mais bonito é mostrar pras pessoas de dentro da favela que elas podiam ter acesso a isso, que a gente podia brincar com isso, com o audiovisual, podia trabalhar com isso, ganhar dinheiro, podia fazer nossa ideologia de vida [...] foi um pensamento que foi amadurecendo junto da CUFA com galera da favela, a galera de fora que queria participar em Madureira, quando a gente começou o curso (GIZZA, 2013, s.p.)

Estes são espaços dotados de grande potência no reconhecimento em comum dos problemas comuns, suscitando estratégias socializadoras e transformadoras do sentido existencial.

Portanto, ao procurar dar cada vez mais voz e legitimidade ao trabalho que já vem sendo executado pela equipe de audiovisual da CUFA Rio, surge o programa de TV Aglomerado, programa de cultura, entretenimento e informação que é fruto da TV Brasil com a Central Única das Favelas (CUFA). Apresentado pelos ativistas sociais, o rapper MV Billl e a rapper Nega Gizza, o programa acontece sob o viaduto Negrão de Lima, em Madureira, subúrbio carioca e sede da CUFARio. O programa que acontece aos sábados tem como objetivo abrir o canal para informações e ações que acontecem pelas ruas das periferias.

Outra experiência que surge desse processo de diálogo da CUFA com o audiovisual éa produtora CUFA Filmes, que consta no seu quadro de profissionais ex-alunos formados pela CUFA audiovisual e que visa um público maior para além da comunidade. 
a maior e mais rica maneira de produzir conhecimento, é dividir conhecimento. (CUFA FILMES, 2011)

Portanto, podemos notar que as mídias podem ser pensados como lugares de divulgação e legitimação de discursos desses movimentos sócio-culturais tomados como bases de ação e voltados para uma dimensão política de reconhecimento social.

De acordo com Dagnino (2000), essa perspectiva faz parte de uma "nova noção de cidadania" - germinada nos anos oitenta e que se estende até os dias atuais -, que possui estreita relação com a trajetória dos "novos movimentos sociais". Essa redefinição cívica abrange, segundo a autora, além do direito à igualdade tradicionalmente reivindicada pelos "movimentos sociais clássicos" por meio da noção de "homogeneização dos direitos" (civis, políticos e sociais) -, e o direito à diferença. Neste sentido, os "novos movimentos sociais" (a partir de uma chave menos igualitária e mais ligada à aceitação da diversidade) encarregam-se do "alargamento do âmbito da cidadania" e da ampliação das arenas públicas. Em outras palavras, os "sujeitos sociais ativos", ou a "sociedade civil emergente" (TELLES, 1994), podem e devem participar da "invenção de uma nova sociedade", isto é, reivindicar o acesso efetivo na "definição do sistema". Para Dagnino (2000), esta deve ser a estratégia de cidadania de "baixo para cima", fazendo emergir nessa esfera uma nova realidade política, marcada pela presença de novos atores e espaços de participação no cenário político local.

A questão da ação política dos grupos sociais adquire grande consistência para a transformação da sociedade. A necessidade de uma profunda transformação cultural; a conquista de uma visão de mundo autônoma em todos os aspectos da existência por parte dos oprimidos; o reconhecimento do fato de todos os homens serem pensadores; a identificação dos "intelectuais orgânicos" no seio de cada classe social representa, por asim dizer, um conjunto de concepções no qual reforça-se a necessidade da compreensão das representações sociais.

\section{A periferia vê o mundo. A periferia vê a periferia. A periferia está falando.}

${ }^{10}$ Cf. NÚCLEO DE COMUNICAÇÃO ALTERNATIVA, s.d.
O Núcleo de Comunicação Alternativa $(\mathrm{NCA})^{10}$, composto por ex-alunos das Oficinas Kinoforum e da ONG Ação Educativa, é um grupo de profissionais que atuam em diferentes áreas da comunicação social. Formado em 2005 no extremo sul de São Paulo, o coletivo trabalha na perspectiva de promover a comunicação popular utilizando-se de ferramentas das mídias como forma de expressão de pensamentos e de produção de intervenções urbanas. Dedicado à pesquisa de linguagem e à potencialização do olhar crítico, o coletivo se utiliza como principal ferramenta do vídeo, além da fotografia, da mídia impressa e da internet, em experimentos com Web TV -, buscando promover um conjunto de atividades de difusão cultural.

No princípio o ímpeto para a formação do Núcleo de Comunicação Alternativa era de ser ouvido, de propor o próprio ponto de vista, algo "nosso", e fugir da imagem estereotipada construída para a periferia e seus moradores. Na verdade, o sujeito da opinião, não seria, portanto, o indivíduo alienado de uma "massa", mas o cidadão esclarecido.

O vídeo popular precisa ser entendido com essa função social-popular, a nosso serviço, o povo. Dando visibilidade àquilo que anda esquecido pelos grandes meios de comunicação. A tecnologia precisa cumprir uma função social. Não podemos cair nessa tendência capitalista da tecnologia por si mesma nem nos transformarmos em reféns dela. A tecnologia da imagem digital precisa mediar as experiências populares. Ela tem que auxiliar, sem ser notada. Cumprir a função e pronto, sumir. (FAGUNDES, 2013, p. 6) 
O acesso às novas tecnologias e as facilidades de filmar, gravar, produzir sons e imagens e distribuí-los a baixo custo nas próprias comunidades periféricas criam novos "espaços públicos" e acrescem a consciência de que a comunicação é um direito fundamental da cidadania. Como exemplo, citamos aqui alguns projetos bem sucedidos realizados - e outros que ainda estão em realização - pelo coletivo. A começar destacamos o documentário Bem morar, trabalho do NCA realizado com as crianças da área em processo de desocupação pelo programa "defesa das águas" no Grajaú, no qual em oficina de vídeo foram registradas as impressões sobre a moradia no bairro. Outro trabalho é o vídeo-poesia gravado com câmera de celular, discutindo a rotina nos trens de São Paulo, que venceu o concurso "Cidade na sua mão", do site Catraca Livre (um projeto de jornalismo comunitário que informa sobre serviços e atividades culturais gratuitos na cidade e região metropolitana de São Paulo). Citamos também a magazine produzida pelo NCA, composta de artigos e textos sobre a produção de vídeo popular na atualidade e suas confluências com experiências históricas. A partir de 2009, passou a ser produzida colaborativamente pelo Coletivo de Vídeo Popular de São Paulo, e no blog do coletivo é possível ter acesso aos pdfs de todas as edições.

Outro projeto de destaque do coletivo é o Festival de Cinema de Várzea, feito na rua, que retoma o espaço público como espaço de lazer, de encontro e de discussão política, em diálogo constante com as pessoas do lugar. A primeira edição do festival ocorreu em Campos de Várzea, do distrito do Grajaú, tendo exibições em vários campos da região, além de ruas de lazer, quadras públicas e associações culturais. O festival é sempre precedido de jogos com clubes da região. Nos oito dias de festival, além dos programas de exibição e dos jogos, o público pode prestigiar apresentações artísticas diversas, como shows, grafitagens, peças de teatro, saraus e rodas de samba. Sendo um festival diferente dos modelos convencionais, o Festival de Cinema de Várzea ocorre de quatro em quatro anos.

Fora isso, desde 2007 o grupo promove o projeto Videoteca Popular, que é um espaço dedicado à disseminação de conteúdos videográficos educativos independentes e do cinema de arte, ofertando regularmente acervo especializado e gratuito, além de exibições regulares através do Cine-Clube Sacola de Imagens toda segunda sexta-feira do mês. O projeto já foi contemplado por dois anos consecutivos no Valorização de Iniciativas Culturais (VAI) da prefeitura e dois anos pelo Ponto de Mídia Livre, tendo somado ao longo de cinco anos um acervo de mais de 900 títulos, dentre DVDs e VHS raros.

Certamente, chega a ser surpreendente o modo como essas redes alternativas de comunicação comunitária a serviço da liberdade de expressão nas periferias brasileiras funcionam, como alimento de crítica conscientizadora que sai do senso comum de percepção. Embora busquem apoio financeiro ou parcerias, esses coletivos funcionam sob a égide de produção feita "na periferia". O que os coletivos reivindicam, cada um a sua maneira, é a possibilidade da própria "periferia" ter iniciativa quanto à sua representação. Aqui ser "da" periferia difere de simplesmente morar nela, pois envolve um sentimento de pertencimento e de identidade.

Reflete-se, ainda, sobre a dimensão da questão da identidade como o elo dos coletivos audiovisuais periféricos, um movimento que na sua prática social consegue simultaneamente trabalhar a autoestima através da conscientização e por meio dela exercitar a cidadania. A participação do cidadão no ambiente social é o que define a cidadania. Acrescento: a questão da cidadania deve estar atrelada à participação do ator social e à pluralidade de seus interesses. 0 protagonismo é entendido no âmbito da assistência social e da educação como "a atuação criativa, construtiva e solidária do jovem, na solução de problemas na comunidade e na vida social mais ampla" (DA COSTA, 2000, p. 22). 
Aqui elaboram claramente uma definição de esfera pública como sendo um espaço de livre acesso onde cidadãos apresentam discursivamente e argumentativamente, na sua capacidade de ação múltipla compartilhada, que se dá pela troca de palavras e na capacidade de julgar de forma aberta com base numa política não só esclarecida, mas que busca incessantemente o esclarecimento. Serem sujeitos da sua própria história, sentarem juntos para trocar experiências são alguns dos aspectos importantes destes coletivos.

\begin{abstract}
Da zona sul de São Paulo um grito ecoa... E vai peregrinando entre os loucos que tem sede de justiça como nós; do alto dos morros o ideal é gritado através de imagens, textos, sons [...] a imagem como grito, o som como movimento, o texto como tato, nossos sentidos audiovisuais seguem fazendo leitura crítica desse mundo globalizado que se propaga e difunde através das mídias [...] Berraremos com arte, já que para mudança não há padrão nem modelo, todas ações unem-se quando o ideal é o mesmo, seja ela artística ou não. Pois assim, não haveremos de morrer por esta JUSTISEDE, buscaremos a fonte, cavaremos poços com câmeras e canetas, levantando a terra com projetores, convocando mais loucos (ou apenas os encontrando), nos re-ligando! No cavoucar de mais poços a descoberta da água, a memória natural da vida humana que brota do seio da terra renovando a esperança por dias melhores. (NÚCLEO DE COMUNICAÇÃO ALTERNATIVA, 2010, s.p.)
\end{abstract}

Num mundo repleto de ambivalências, as grandes metrópoles como centros de difusão e consumo de imaginários culturais, repercute o jogo de imagens e excessos de significações do próprio ambiente em que o mercado ganha relevo e corteja a juventude, instituindo-a como protagonista da maioria de seus mitos como consumidores efetivos e imaginários (MORIN, 1996). O eu indefinido a procura de uma identidade sempre perseguida e nunca alcançada agarra-se ansioso a pequenos sinais de auto-expressão publicamente fornecidos (BAUMAN, 2000).

Essa natureza discursiva da localização social dos indivíduos apontado pelo sociólogo Zygmunt Bauman, e em outro sentido também mencionado por Edgar Morin, que movimenta a dinâmica do pertencimento, não elimina no todo o sentido da objetivação de si, já que o percurso que remete à ideia de pertencimento demarca uma lógica interna do vivido no momento dinamizado a partir de uma causa, os trajetos, as escolhas, com isso nos convidando a espaços experimentais no qual somos chamados a interagir.

Os coletivos audiovisuais periféricos procuram dar ênfase sobre a necessidade de uma relação de correspondência entre o emissor e o receptor, cada um ao seu modo, destacando a transparência na narrativa. Este por sua vez entrecruza com o olhar de Bourdieu (1998) quando afirma em seus estudos que o grande problema da imprensa e da televisão, por exemplo, não é mais tanto o que elas são capazes de mostrar, mas o que ainda podem apagar e ocultar. Cabe salientar que no campo da cultura midiática, Baudrillard (1998) destaca que a abstração encontra sua realização num modelo de informação generalizada a devorar o social, prestes a destruir a comunicação ao convertê-la em pura encenação de si mesma: em simulacro. Isso significa o mesmo que o cadáver do real, onde nada mais representa como verdadeiro ou falso, cuja realidade passa a ser apenas um conceito no qual a subjetividade humana torna-se um conjunto de funções inúteis diante da instantaneidade das coisas na informação globalizada.

Por outro viés, contudo, diversos teóricos vêm retomando a crítica do discurso concebida na intensificação da circulação dos fluxos culturais para demonstrar a existência inegável na qual a tendência à globalização da cultura não resulta na homogeneização do planeta, mas num mundo cada vez mais mestiço. Atualmente Canevacci (2000), desdobrando os conceitos de hibridação e mestiçagem, engendra na explicação das combinações e reciclagens dos fluxos culturais 
internacionais pelas culturas locais. Assim, contra o poder linear da dialética histórica universalizante, o sincretismo (território marcado pelas travessias entre correntes extraterritoriais não só de etnias, mas também de estilos de vida, visões de mundo e sensibilidades estéticas) aparece como modelo, onde os símbolos são vistos como estendidos sob profundas instâncias de simbolização, determinadas por tendências culturais múltiplas que fragmentam e remastigam todo o código.

Outro antropólogo, o indiano Appadurai, citado por Roberston (1997), acredita que os instrumentos de homogeneização trazidos pela globalização (armamentos, técnicas publicitárias, hegemonia de certos idiomas, moda) ficam de fato absorvidos pelas economias políticas e culturais locais, unicamente para serem repatriados no tecido urbano como diálogos heterogêneos, onde o estado-nação se incumbe de um papel cada vez mais delicado.

Nota-se evidenciar a pertinência das categorias de hegemonia e resistência para se pensar o modo como as identidades são construídas através das relações de continuidade, ruptura e hibridização entre os sistemas globais e locais, além de tradicionais e modernos imbricados no desenvolvimento da cultura. Ademais, a atual complexidade dos fenômenos culturais exige analisar as identidades como processos de negociação "na medida em que são híbridas, dúcteis e multiculturais" (CANCLINI,1996, p. 151).

Ao resgatar essa dimensão social da subjetividade propomos simplesmente evitar modelar o indivíduo com base em um único sujeito determinante, mas em diferentes circunstâncias do espaço híbrido, dando margem ao aparecimento de um eu plural inquieto diante das divergentes multiplicidades interior/exterior numa resposta diante das limitações postas pela contemporaneidade.

As produções e exibições audiovisuais no espaço periférico alicerçam nos princípios de comunidade, quais sejam, e em comum implicam a participação ativa, horizontal e democrática dos cidadãos; experiências compartilhadas; criações próprias e identificação local - é uma comunicação que se compromete, acima de tudo, com os interesses da "periferia" onde se localiza.

Trata-se, como diria Jesus Martin-Barbero, de um dos expoentes dos Estudos Culturais Latinoamericano em reconhecer que os estudos de comunicação não devem necessariamente recair sobre as suas especificidades técnicas, mas sobre o lugar em que a comunicação reside no campo da cultura. Dessa forma, "a comunicação se tornou para nós questão de mediações mais que de meios, questão de cultura e, portanto, não só de reconhecimento, mas reconhecimento" (MARTíN-BARBERO, 1997, p. 32). Mediações, segundo o autor, seriam as articulações entre práticas de comunicação e movimentos sociais, que permitem compreender a "natureza comunicativa" do sujeito, outrora de mero decodificador para produtor do processo comunicativo. Trata-se de um processo comunicativo em que segmentos organizados da população submetidos a condições de subalternidade se tornam protagonistas da comunicação.

\section{Considerações finais}

É preciso reconhecer a dimensão produtiva desses coletivos periféricos como agentes que estão transformando realidades locais. A participação/intervenção dos jovens periféricos por meio dos movimentos sociais e culturais nas decisões que o Estado vem tomando atualmente no âmbito das políticas sociais contribui para o fortalecimento da sociedade civil, pois favorece formas de organização popular que, em nosso entendimento, expressam a face positiva da relação entre cidadania e igualdade.

A diversidade desses agrupamentos traduz diferentes carências que vão unir e movimentar os indivíduos dentro da metrópole numa mobilização rumo às 
coletividades ao assegurar a liberdade de fazer-se representar - o que implica na autonomia desses espaços que garantam o reconhecimento de exprimir o desejo de participação.

Assim, a esfera da visibilidade conclama a sociabilidade e a comunicação. As identidades associativas periféricas nada mais são do que agentes de liberdade, de igualdade, sistemas de forças e conflitos, cuja participação envolve a intensa busca pelo domínio do esclarecimento na superação dos indivíduos supérfluos.

Vemos que diante da atuação dos coletivos periféricos, vinculados às demandas do audiovisual enquanto ferramenta de comunicação e educação, a conquista da cidadania deixa de ser pensada exclusivamente em termos da vigência de direitos reconhecidos pelo Estado e passa a compor um "catálogo" de demandas e atitudes que cobram reconhecimento e respeito para si. Em outros termos, a cidadania passa a se orientar num terreno em que sua definição não está dada $a$ priori nem de uma vez por todas, tampouco se expressa uniformemente.

A dimensão ativa e criativa desses sujeitos no processo de construção do conhecimento indica que a partir de meros expectadores colocam suas marcas pessoais, processando e transformando aquele conhecimento em outro, num processo de significação e ressignificação dos objetos. Nos referimos à polifonia da cidadania, as vozes diversas que convocam o referencial de cidadania e que o fazem de forma diferenciada.

Torna-se patente, contudo, que ignorar a existência de tais coletivos e o impacto político que estes são capazes de produzir significa deixar de lado um real fato novo, sobretudo no momento em que podemos ter uma contribuição à democratização dos sistemas políticos pela mudança nas regras de procedimento às políticas públicas voltadas aos moradores das periferias dos grandes centros urbanos do Brasil e a ampliação dos limites dessa política.

\section{Referências Bibliográficas}

AÇÃO EDUCATIVA. Página Inicial. Disponível em: <http://www.acaoeducativa. org.br>. Acesso em: 11 jan. 2013.

ARENDT, H. O que é liberdade. In: . Entre o passado e o futuro. Tradução Mauro W. Barbosa de Almeida. São Paulo: Perspectiva, 1979. p. 188-220.

ASSOCIAÇÃO CULTURAL KINOFORUM. Página Inicial. Disponível em: <http:// www.kinoforum.org.br>. Acesso em: 11 jan. 2013.

ASSOCIAÇÃO AUDIOVISUAL CINESCADÃO. Página Inicial. Disponível em: < https:// cinescadao.wordpress.com>. Acesso em: 23 jul. 2013.

BAUDRILLARD, J. The consumer society: myths and structures. Londres: SAGE Publications, 1998.

BAUMAN, Z. Liquid modernity. Cambridge: Polity Press, 2000.

BECOS E VIELAS. Página Inicial. Disponível em: < http://becosevielaszs.blogspot. com.br>. Acesso em: 12 jul. 2013.

BONDUKI, N. G.; ROLNIK, R. Periferia da Grande São Paulo: reprodução do espaço como expediente de reprodução da força de trabalho. In: MARICATO, E. (Org.). A produção capitalista da casa (e da cidade) no Brasil industrial. 2. ed. São Paulo: AlfaÔmega, 1982. 
BOURDIEU, P. On television. Nova York: The New Press, 1998.

CALDEIRA, T. City of walls: crime, segregation, and citizenship in São Paulo. Berkeley: University of California Press, 2000.

CANCLINI, N. G. Consumidores e cidadãos. Rio de Janeiro: UFRJ, 1996.

CANEVACCI, M. A cidade polifônica: ensaio sobre a antropologia da comunicação urbana. São Paulo: Studio Nobel, 2000.

CASTELLS, M. A sociedade em rede. 2. ed. Tradução Majer, R.V \& Gerhardt, K.B. São Paulo: Paz e Terra, 1999.

CUFA. Página Inicial. Disponível em: < http://www.cufa.org.br >. Acesso em: 29 abr. 2013

CUFA FILMES. A produtora, o portigólio, a equipe. 2011. Disponível em: <http:// www.cufafilmes.com.br/site/?pagina=about-us>. Acesso em: 29 abr. 2013.

DA COSTA, A. C. G. Protagonismo juvenil: adolescência, educação e participação. Salvador: Fundação Odebrecht, 2000

DAGNINO, E. Cultura, cidadania e democracia. A tranformação dos discursos e práticas na esquerda latino-americana. In: DAGNINO, E.; ESCOBAR, A.; ALVAREZ, S. (Orgs.). Cultura e política nos movimentos sociais latinoamericanos: novas leituras. Belo Horizonte: UFMG, 2000. p. 61-102.

FAGUNDES, D. Mas que mer... cadoria!!! Revista Video Popular - contra o cinema mercadoria, dez. 2010. Disponível em: <http://videopopular.files.wordpress. com/2011/02/revista_video_popular_12_2010_levefinal.pdf. Acesso em: 13 fev. 2013>.

GALVÃO, F. Flávio Galvão: entrevista [27 de maio 2013]. Entrevistador: R. Martins. São Paulo: [arquivo pessoal].

GIZZA, N. Nega Gizza: entrevista [18 de abril de 2013]. Entrevistador: R. Martins. Rio de Janeiro: [arquivo pessoal].

HALL, S. The work of representation. In: HALL, S. (Ed.). Representation: cultural representation and cultural signifying practices. Londres/Thousand Oaks/Nova Delhí: Sage/Open University, 1997. p. 13-64.

HAMBURGER, E. Violência e pobreza no cinema brasileiro recente. Novos estudos, São Paulo, 2007, n. 78, p. 113-128.

HONNETH, A. The struggle for recognition: the moral grammar of social conflicts. Cambridge: Polity Press, 1996.

HUTCHISON, R.; HAYNES, B. D. (Eds.) Introduction. In: The gueto: contemporay global issues and controversies. VII - XLIII. Westview Press: Philadelphia, 2012.

KOWARICK, L. A espoliação urbana. 2. ed. Rio de Janeiro: Paz e Terra, 1983. . Escritos urbanos. São Paulo: Editora 34, 2000.

LEITE, M. P. Na tela o povo e a nação: classes populares e periferias em imagens. In: MEDEIROS, B. F.; COSTA, M. H. (Orgs.). Imagens marginais. Natal: EDUFRN, 2006. p. 39-56.

MARTÍN-BARBERO, J. Comunicação plural: alteridade e sociabilidade. Comunicação \& Educação, São Paulo, n. 9, ano III, maio/ago., p. 39-48, 1997. 
. Dos meios às mediações: comunicação, cultura e hegemonia. Rio de Janeiro: UFRJ, 1997.

MARTINS, R. Hip-hop: o estilo que ninguém segura. São Paulo: Esetec, 2005.

MELUCCI, A. An introduction to study of social movements. Social Research, vol. 52, n. 4, Winter, p. 749-787, 1985.

MORIN, E. Cultura de massas no século XX: o espírito do tempo. 2. ed. Tradução Maria Elisa Cevasco. São Paulo: Ática, 1996.

MOSCOVICI, S. Representações sociais da psicanálise. São Paulo: Zahar, 1978.

NAKANO, A. K. Quatro COHABs da zona leste de São Paulo: território, poder e segregação. 2002. 245f. Dissertação (Mestrado em Habitat) - Faculdade de Arquitetura e Urbanismo, Universidade de São Paulo, São Paulo, 2002.

NOVAES, R. Os jovens de hoje: contextos, diferenças e trajetórias. In: ALMEIDA, M. I. M.; EUGENIO, F. (Orgs.). Culturas jovens: novos mapas do afeto. Rio de Janeiro: Jorge Zahar, 2006. p. 105-120.

NÚCLEO DE COMUNICAÇÃO ALTERNATIVA. 2007. Disponível em: <http://www. ncanarede.blogspot.com.br>. Acesso em: 11 jan. 2013.

NÚCLEO DE COMUNICAÇÃO ALTERNATIVA. Diálogos. Revista Video Popular contra o cinema mercadoria, dez. 2010. Disponível em: <http://videopopular. files.wordpress.com/2011/02/revista_video_popular_12_2010_levefinal.pdf. Acesso em: 13 fev. 2013>.

PAOLI, M. C.; TELLES, V. S. Direitos sociais conflitos e negociações no Brasil contemporâneo. In: DAGNINO, E.; ESCOBAR, A.; ALVAREZ, S. (Orgs.). Cultura e política nos movimentos sociais latinoamericanos: novas leituras. Belo Horizonte: UFMG, 2000. p. 103-148

ROBERTSON, R. Social theory, cultural relativity and the problem of globality. In: KING, A. D. (Ed.). Culture, globalization, and the world-system: contemporary condition for the representation of identity. Minneapolis: University of Minnesota Press, 1997.

TELLES, V. S. Sociedade civil e a construção de novos espaços públicos. In: DAGNINO, E. (Org.). Anos 90 - política e sociedade no Brasil. São Paulo: Editora Brasiliense, 1994.

VALA, J.; MONTEIRO, M. B. Psicologia social. Lisboa: Fundação Calouste Gulbenkian, 2004.

VALLADARES, Licia do Prado. A invenção da favela: do mito de origem à favela. com. Rio de Janeiro: Editora FGV, 2005. 